\title{
Development of Integrated Motor Assist Hybrid System: Development of the 'Insight', a Personal Hybrid Coupe
}

\author{
Kaoru Aoki, Shigetaka Kuroda, Shigemasa Kajiwara, \\ Hiromitsu Sato and Yoshio Yamamoto \\ Honda R\&D Co.,Ltd.
}

Permission is hereby granted for a copyright release fee of $\$ 300$ per paper. An invoice will follow under separate cover. Please be sure to include the following credit statement with these papers:

\section{"(C) Society of Automotive Engineers, Inc. The following papers are} published on this web-site with permission from the Society of Automotive Engineers, Inc. As a user of this web-site, you are permitted to view these papers on-line, download the PDF file and to print a copy at no cost for your use only. Dowloaded PDF files and printouts of SAE papers

contained on this web-site may not be copied or distributed to others or for the use of others." 
The appearance of this ISSN code at the bottom of this page indicates SAE's consent that copies of the paper may be made for personal or internal use of specific clients. This consent is given on the condition, however, that the copier pay a $\$ 7.00$ per article copy fee through the Copyright Clearance Center, Inc. Operations Center, 222 Rosewood Drive, Danvers, MA 01923 for copying beyond that permitted by Sections 107 or 108 of the U.S. Copyright Law. This consent does not extend to other kinds of copying such as copying for general distribution, for advertising or promotional purposes, for creating new collective works, or for resale.

SAE routinely stocks printed papers for a period of three years following date of publication. Direct your orders to SAE Customer Sales and Satisfaction Department.

Quantity reprint rates can be obtained from the Customer Sales and Satisfaction Department.

To request permission to reprint a technical paper or permission to use copyrighted SAE publications in other works, contact the SAE Publications Group.

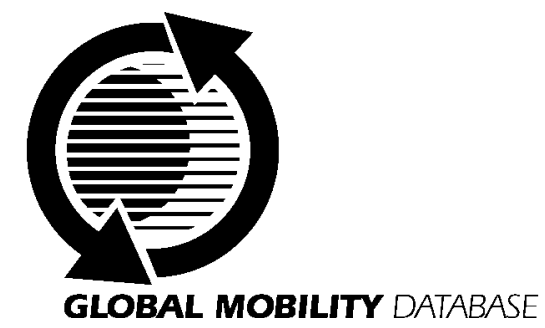

All SAE papers, standards, and selected books are abstracted and indexed in the Global Mobility Database

No part of this publication may be reproduced in any form, in an electronic retrieval system or otherwise, without the prior written permission of the publisher.

\section{ISSN 0148-7191}

Copyright $\odot 2000$ SAE International

Positions and opinions advanced in this paper are those of the author(s) and not necessarily those of SAE. The author is solely responsible for the content of the paper. A process is available by which discussions will be printed with the paper if it is published in SAE Transactions. For permission to publish this paper in full or in part, contact the SAE Publications Group.

Persons wishing to submit papers to be considered for presentation or publication through SAE should send the manuscript or a 300 word abstract of a proposed manuscript to: Secretary, Engineering Meetings Board, SAE.

\section{Printed in USA}




\title{
Development of Integrated Motor Assist Hybrid System: Development of the 'Insight', a Personal Hybrid Coupe
}

\author{
Kaoru Aoki, Shigetaka Kuroda, Shigemasa Kajiwara, \\ Hiromitsu Sato and Yoshio Yamamoto \\ Honda R\&D Co.,Ltd.
}

Copyright (? 2000 Society of Automotive Engineers, Inc.

\begin{abstract}
This paper presents the technical approach used to design and develop the powerplant for the Honda Insight, a new motor assist hybrid vehicle with an overall development objective of just half the fuel consumption of the current Civic over a wide range of driving conditions. Fuel consumption of $35 \mathrm{~km} / \mathrm{L}$ (Japanese $10-15$ mode), and $3.4 \mathrm{~L} / 100 \mathrm{~km}(98 / 69 / \mathrm{EC})$ was realized. To achieve this, a new Integrated Motor Assist (IMA) hybrid power plant system was developed, incorporating many new technologies for packaging and integrating the motor assist system and for improving engine thermal efficiency. This was developed in combination with a new lightweight aluminum body with low aerodynamic resistance. Environmental performance goals also included the simultaneous achievement of low emissions (half the Japanese year 2000 standards, and half the EU2000 standards), high efficiency, and recyclability. Full consideration was also given to key consumer attributes, including crash safety performance, handling, and driving performance.
\end{abstract}

\section{INTRODUCTION}

To reduce the automobile's impact on society and the environment requires that it be increasingly cleaner and more energy efficient. The issues of energy conservation, ambient air quality, and reduction in $\mathrm{CO}_{2}$ emissions are increasing raised as global environmental concerns. One solution for dealing with these issues is the hybrid automobile. Honda has developed and introduced to several major markets worldwide the Insight, a new generation of vehicle design. The Insight combines a hybrid power train with advanced body technology features to meet an overall goal of achieving the highest fuel economy practical.

The hybrid power train is a motor assist parallel configuration, termed IMA for 'Integrated Motor Assist'. This power train combines a highly efficient electric motor with a new small displacement VTEC engine, a lightweight aluminum body, and improved aerodynamics to realize
$3.4 \mathrm{~L} / 100 \mathrm{~km}\left(\mathrm{CO}_{2}: 80 \mathrm{~g} / \mathrm{km}\right)$ on $98 / 69 / \mathrm{EC}$ fuel economy. Low emissions performance was also targeted with emission levels achieving the EU2000.

In addition to recapturing deceleration energy, the integrated motor provides high torque assist during typical urban driving accelerations. This allows a significant reduction in engine displacement and higher engine efficiency. Sustained hill climbing performance and high speed cruising capability are assured by a power-toweight ratio of approximately $56 \mathrm{~kW}$ per metric ton. New engine technology includes the application of a new VTEC (Variable valve Timing and valve lift, Electronic Control) cylinder head design promoting high efficiency and fast catalyst activation, and a new lean NOx catalyst system which promotes lean burn combustion and a reduction in emissions. Extensive friction and weight reducing features are also applied.

\section{DEVELOPMENT TARGETS AND CONCEPT}

Development was aimed at the achievement of extremely low fuel consumption. We set a target of twice the fuel economy of the current production Civic, Honda's representative high fuel economy car at $7.0 \mathrm{~L} / 100 \mathrm{~km}(93 / 116 /$ $E C)$. As a result, the Insight has the lowest fuel consumption in the world, among gasoline passenger cars.

Exhaust emission performance often tends to be sacrificed for the sake of low fuel consumption. However, we also decided to match the low emissions performance achieved by other mass production cars.

Consideration was also given to recyclability (another important environmental issue), crash safety performance, and the basic car characteristics including handling and styling.

Summarizing the above, our development targets were as follows:

- The best fuel consumption performance in the world

- Ultra-low exhaust emissions

- Superior recyclability 
- The world's highest level of crash safety performance

- Advanced styling

- Practical features and responsive handling

- Comfortable two-seat configuration with personal utility space

\section{POLICIES FOR FUEL CONSUMPTION REDUCTION}

In order to establish the technical approach for achieving the fuel consumption target, we conducted a detailed analysis of the energy consumption of the base car, a Civic equipped with a 1.5 liter engine. We found that it was useful to divide the targeted efficiency gains roughly into thirds, as shown in Fig. 1, in order to achieve the low fuel consumption and numerous other above-mentioned goals. These divisions are as follows.

- Improvement of the heat efficiency of the engine itself

- Recovery of braking energy and employment of idle stop using a hybrid power plant

- Car body technologies including reduction of weight and reduced aerodynamic and rolling resistance.

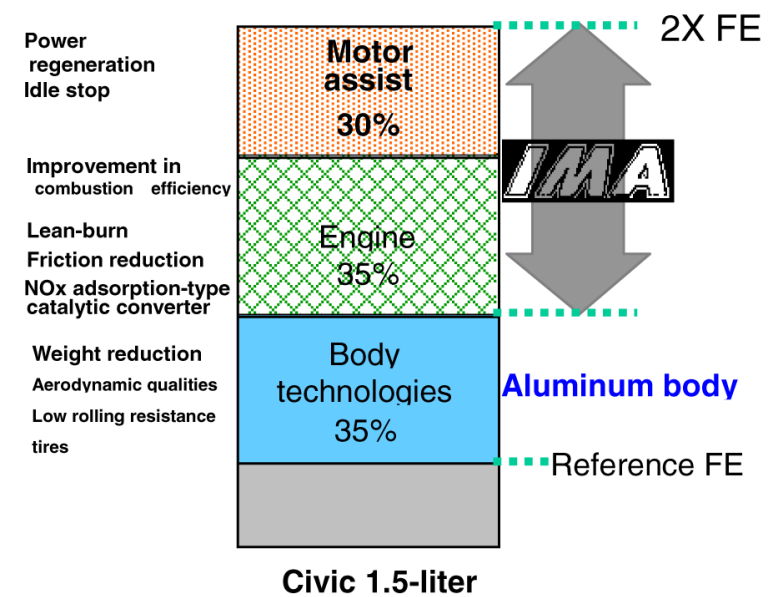

Figure 1. Target of double the fuel economy of CIVIC

Aiming to establish a benchmark for 21st century automobile power trains, we developed this new Integrated Motor Assist power train. This power train simultaneously achieves both extremely low fuel consumption of $3.4 \mathrm{~L} / 100 \mathrm{~km}$, and low exhaust gas emission performance, befitting a next-generation car.

This paper reports on the newly developed IMA system, including the lean burn engine, electric motor, power control unit, battery technology, and exhaust emission control technology used in the "Honda Insight".

\section{AIM OF THE IMA SYSTEM}

While developing this next-generation IMA hybrid system, we incorporated as many currently achievable technologies and techniques as possible, in order to achieve the "world's lowest fuel consumption".
The following four system development themes were established in order to meet this target.

1. Recovery of deceleration energy

2. Improvement of the efficiency of the engine

3. Use of idle stop system

4. Reduction of power train size and weight

\section{OVERVIEW OF THE IMA SYSTEM}

5.1. SYSTEM CONFIGURATION - As shown in Fig. 2, the IMA system uses the engine as the main power source and an electric motor as an auxiliary power source when accelerating. Using a motor as an auxiliary power source simplifies the overall system and makes it possible to use a compact and lightweight motor, battery, and power control unit (PCU).

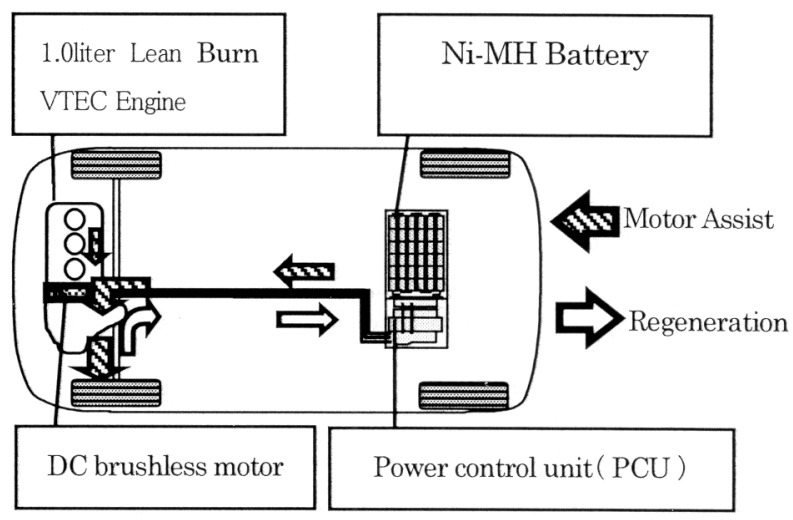

Figure 2. IMA System

A permanent magnet DC brushless motor is located between the engine and the transmission. When decelerating, the rate of deceleration is calculated for each gear and the PCU controls the motor to generate electricity (recover energy), which charges a nickel-metal hydride battery. When accelerating, the amount of auxiliary power provided (hereafter called "assist") is calculated from the throttle opening, engine parameters, and battery state of charge. The PCU controls the amount of current flowing from the battery to the drive motor

\subsection{RECOVERY OF DECELERATION ENERGY -} Recovering deceleration energy through regeneration makes it possible to supplement the engine's output during acceleration and reduce the amount of fuel consumed. Reducing resistance due to running losses, including engine frictional losses, increases the available energy for regeneration. In particular, minimizing the engine displacement is an effective means of reducing friction. Engine displacement reduction also has several other benefits, such as weight reduction and increased thermal efficiency. The IMA system effectively increases the amount of regeneration during deceleration by optimizing the engine and transmission specifications. 
5.3. REDUCTION OF ENGINE DISPLACEMENT Reducing engine displacement is a very important factor in improving fuel economy of a hybrid drive train. However, modern automobiles have to perform over a wide dynamic range. Reducing the displacement is equivalent to lowering the basic performance characteristics of the car. As shown in the output characteristics graph in Fig. 3, the IMA system assists the engine in the low rpm range by utilizing the hightorque performance characteristic of electric motors. The motor can increase overall toruque by over $50 \%$ in the lower rpm range used in normal driving. Output in the high rpm range is increased by using a Variable valve Timing and valve lift Electronic Control (VTEC) engine. Thus sufficient peak power is assured and makes it possible to use a new, small displacement 1.0 liter engine.

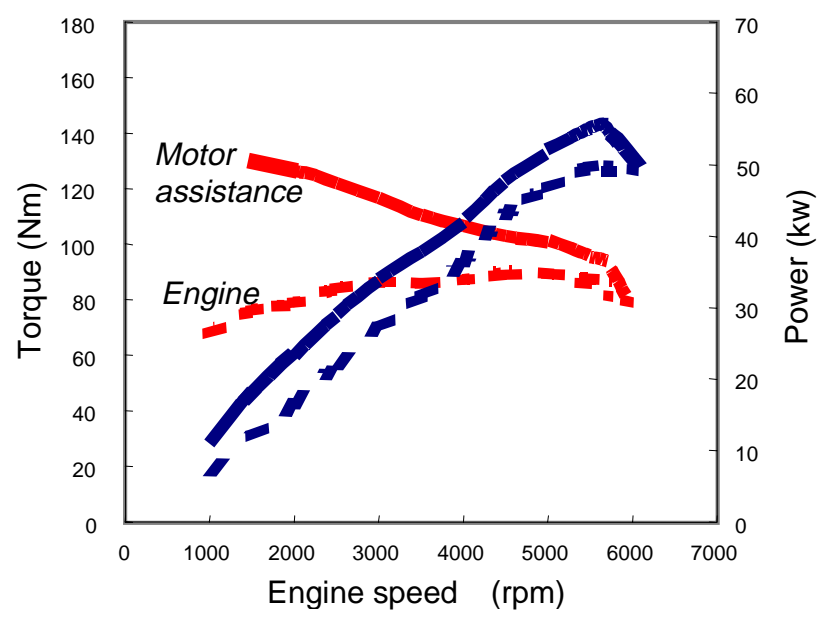

Figure 3. Output performance of IMA SYSTEM

Assist from the electric motor while accelerating is a very efficient means of reducing the amount of fuel consumed.

5.4. ACHIEVING LEAN BURN ENGINE OPERATION Assist from the electric motor, based upon the throttle opening, creates quite linear torque characteristics. This, in turn, improves driveability. In addition, motor assist is also provided under moderate load conditions to broaden the lean-burn operating range, bringing out the full potential of the newly developed lean burn engine.

5.5. IDLE STOP SYSTEM - Stopping the engine rather than idling at stops is also an effective means for reducing fuel consumption. In order to restart the engine with the minimum amount of fuel consumption, the engine is quickly cranked to $600 \mathrm{rpm}$ or more by the hightorque integrated motor before ignition occurs, as shown in Fig. 4. This makes it possible to minimize the amount of fuel consumed, in addition to the fuel saved by not running the engine at idle.

There are many issues to be considered when performing idle stop. These include judging the driver's intent to stop, preparing for the restart, providing a smooth feeling of deceleration, and minimizing vibration of the car body when the engine stops.

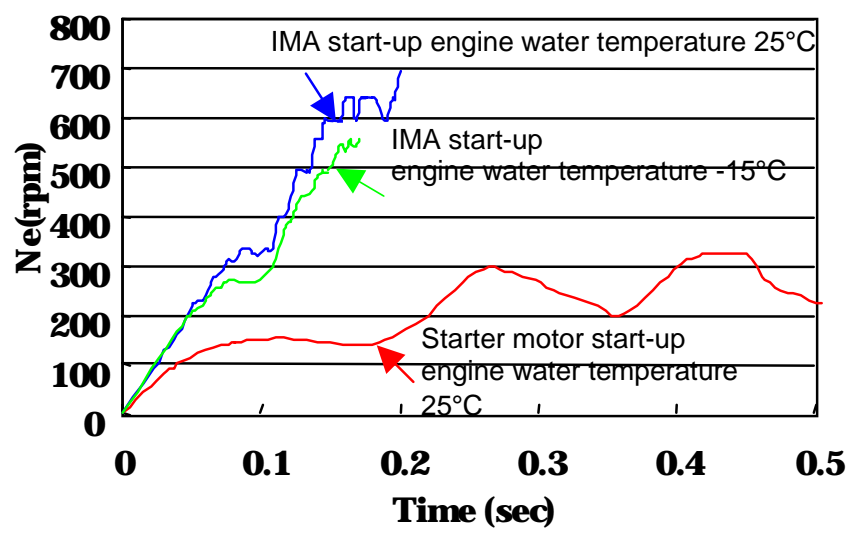

Figure 4. The number of cranking in the engine start

This IMA system results in the achievement of both very quick restarts and exceptionally smooth starts.

\section{MOTOR ASSIST MECHANISM}

6.1. DEVELOPMENT OBJECTIVES - By limiting the IMA motor functions to assistance and regeneration, development themes were established to achieve the following two points.

1. A simple and compact structure

2. A system weight of $10 \%(80 \mathrm{~kg})$ or less of the completed car weight

6.2. THIN PROFILE DC BRUSHLESS MOTOR - A thin and compact $D C$ brushless motor with engine assist and energy regeneration functions was coupled to the engine crank-shaft (Fig. 5).

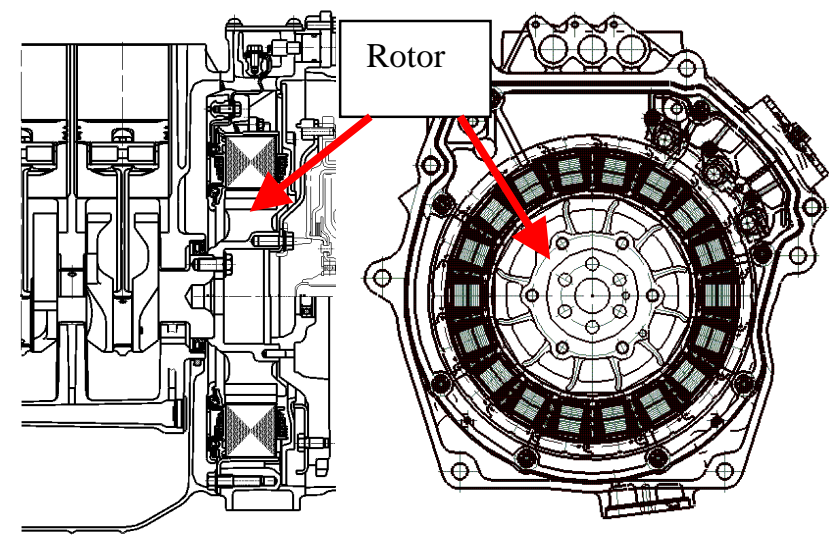

Figure 5. Section view of Motor

This is a high efficiency, compact, and lightweight permanent magnet-type three-phase synchronous electric motor with a maximum output of $10 \mathrm{~kW}$. In addition to developing technologies to reduce the weight and increase efficiency, we also aimed to make the motor as thin as possible in order to achieve a compact power train. Lost wax precision casting process was used for the rotor, rotating by bending coupled to the crankshaft. This achieves high strength and lighter weight (approximately -20\%) compared with normal cast 
products. For the rotor magnets, further improvements were made to the neodymium-sintered magnets used in the HONDA EV PLUS, realizing approximately $8 \%$ greater torque density and improved heat resistance. This design also results in a motor structure that does not require a cooling system. A split stator structure with salient pole centralized windings was developed and used to reduce the motor axial width. A split stator was adopted to drive the rotor. This makes it possible to use the salient pole centralized windings, which are both more compact and efficient than the conventional coil wave winding method, as shown in Fig. 6. In addition, centralized distribution bus rings (Fig. 7) formed from copper sheets were used for the harness that supplies electricity to the coils on both sides of the stator. This results in an extremely compact and simple structure. These improvements achieve an extremely thin motor with a width of only $60 \mathrm{~mm}$. This represents a $40 \%$ reduction in width compared to conventional technology.
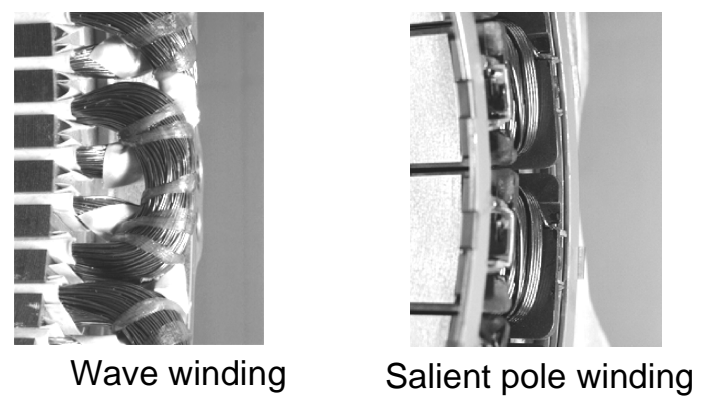

Figure 6. Compare of winding

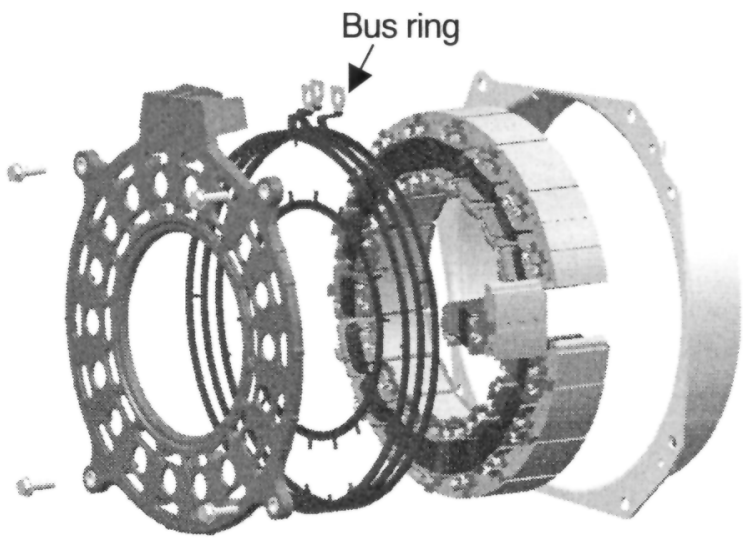

Figure 7. Cut view of Motor

6.3. NICKEL-METAL HYDRIDE (NI-MH) BATTERY - A nickel-metal hydride battery is used to store and provide electrical energy for the motor assist. This is an advanced battery which has already achieved proven results in the high specific energy version used for the HONDA EV PLUS electric vehicle. The hybrid vehicle battery features stable output characteristics, regardless of the state-of-charge status. It is also extremely durable in this application. The battery pack has an integrated structure consisting of 20 modules, each having six
D-size cells connected in series, arranged in a lattice formation. These $1201.2 \mathrm{~V}$ cells are all connected in series for a total battery pack voltage of $144 \mathrm{~V}$.

6.4. POWER CONTROL UNIT (PCU) - The PCU performs precise control of motor assist/regeneration and supplies power to the $12 \mathrm{~V}$ power source. It has built-in cooling functions, which give it a lightweight, efficient and compact structure. Significant weight reduction was achieved by integrating an air cooling system using highly efficient cooling fins and a magnesium heat sink case.

The inverter for the drive motor, which is the most important component within the PCU, has switching elements integrated into a single module for generating the three-phase AC current. These were separate components on the EV PLUS. The drive circuit has been miniaturized and converted to an IC using high density integration. These improvements have resulted not only in significant weight reduction, but have also improved the power conversion efficiency. Further, using phase control to drive the motor at very high efficiencies reduces the amount of heat produced and makes it possible to use a lightweight and simple air-cooling system. (Fig. 8)

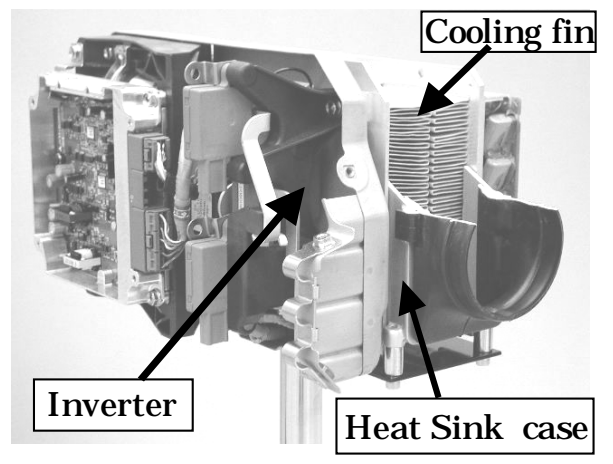

Figure 8. Cut view of PCU

\section{ENGINE}

7.1. DEVELOPMENT OBJECTIVES - The following four points were set as development themes in order to achieve low fuel consumption over a wide range of operating conditions.

1. Improvement of thermal efficiency

2. Reduction of mechanical losses (-10\% compared with conventional designs )

3. Reduction of size and weight (lightest weight in its class)

\section{Achievement of half the EU2000 standards}

7.2. ENGINE OVERVIEW AND SPECIFICATIONS The engine specifications are shown in Table 1 and the main new features and their purposes are shown in Table 2. 
Table 1 Engine specification

\begin{tabular}{|l|c|}
\hline Engine type & Water cooled gasoline engine \\
\hline Cylinder layout & Inline 3-cylinder \\
\hline Bore×stroke $(\mathrm{mm})$ & $\phi 72 \times 81.5$ \\
\hline Displacement $\left(\mathrm{cm}^{3}\right)$ & 995 \\
\hline Compression ratio & 10.8 \\
\hline Valve train & $\begin{array}{c}\text { SOHC VTEC } \\
\text { 4valve per cylinder }\end{array}$ \\
\hline Cam shaft drive train & Chain drive \\
\hline Max.power $(\mathrm{kW} / \mathrm{pm})$ & $50 / 5700$ \\
\hline Max.torque $(\mathrm{Nm} / \mathrm{rmm})$ & $91 / 4800$ \\
\hline
\end{tabular}

Table 2 New technology objects

\begin{tabular}{|c|c|c|c|}
\hline & $\begin{array}{l}\text { Low fuel } \\
\text { consumption }\end{array}$ & $\begin{array}{l}\text { Low } \\
\text { emission }\end{array}$ & $\begin{array}{l}\text { Small } \\
\text { /weight }\end{array}$ \\
\hline $\begin{array}{l}\text { New SOHC-VTEC } \\
\text { cylinder-head }\end{array}$ & 0 & 0 & 0 \\
\hline $\begin{array}{l}\text { VTEC In-Built } \\
\text { Roller rocker arm }\end{array}$ & 0 & & 0 \\
\hline $\begin{array}{l}\text { Aluminum exhaust } \\
\text { roller rocker-arm }\end{array}$ & 0 & & 0 \\
\hline $\begin{array}{l}\text { Cam shaft chain } \\
\text { drive system }\end{array}$ & 0 & & 0 \\
\hline $\begin{array}{l}\text { Chamber polished } \\
\text { piston }\end{array}$ & 0 & & \\
\hline $\begin{array}{l}\text { Dimple treatment } \\
\text { piston }\end{array}$ & 0 & & \\
\hline $\begin{array}{l}\text { Cr-N coated } \\
\text { oil ring }\end{array}$ & 0 & & \\
\hline $\begin{array}{l}\text { Low tension } \\
\text { Piston ring }\end{array}$ & 0 & & \\
\hline $\begin{array}{l}\text { Arrangement of off- } \\
\text { set cylinder }\end{array}$ & 0 & & \\
\hline $\begin{array}{l}\text { Carbonized } \\
\text { connecting rod }\end{array}$ & 0 & & 0 \\
\hline $\begin{array}{l}\text { Magnesium oil pan } \\
\text { \& ECU case }\end{array}$ & & & 0 \\
\hline $\begin{array}{l}\text { Expansion of } \\
\text { Plastic Parts }\end{array}$ & & & 0 \\
\hline $\begin{array}{ll}\text { Rear } & \text { Exhaust } \\
\text { system } & \end{array}$ & & 0 & 0 \\
\hline $\begin{array}{l}\text { Cylinder-head with } \\
\text { Integrated exhaust } \\
\text { manifold }\end{array}$ & 0 & 0 & \\
\hline $\begin{array}{l}\text { Lean NOx } \\
\text { Catalyst }\end{array}$ & 0 & 0 & \\
\hline
\end{tabular}

First, a displacement of approximately $1000 \mathrm{~cm}^{3}$ was considered optimal for this vehicle with the IMA system, so a 3-cylinder engine was selected to minimize combustion chamber surface-to-volume ratio and mechanical losses. (Fig. 9)

7.3. FUEL CONSUMPTION - Engine displacement could be reduce considerably in the motor assist powertrain because of the motor assist enhancement of low rpm torque, and also VTEC for sufficient peak power output from the engine. A key feature of this engine is the significant improvement in combustion efficiency through lean burn technology. Technologies adopted to make this possible include new intake swirl ports, which enhance the swirl (mixture formation) inside the cylinders. A compact combustion chamber and a high compression ratio also help by improving the indicated heat efficiency. This result in significantly shorter combustion times compared to conventional lean burn engines, allowing combustion in a leaner range with a higher air-fuel ratio. This significantly improves the fuel consumption.

The new high swirl ports and compact combustion chamber are evolutions based on conventional VTEC lean burn technology. In the conventional VTEC engine, swirl is produced by keeping one intake valve closed in low speed operating conditions. However, in this engine the intake valves and intake ports are arranged more vertically to produce strong eddies in the mixture flowing into the cylinders.

The conventional VTEC configuration has the inlet and exhaust rocker arms each supported by a separate rocker shaft. The new VTEC mechanism shown in Fig.10 combines these into a single rocker shaft, thus realizing a significant reduction in size. In addition, it narrows the valve included angle from $46^{\circ}$ to $30^{\circ}$, allowing a high swirl port shape and a very compact combustion chamber.

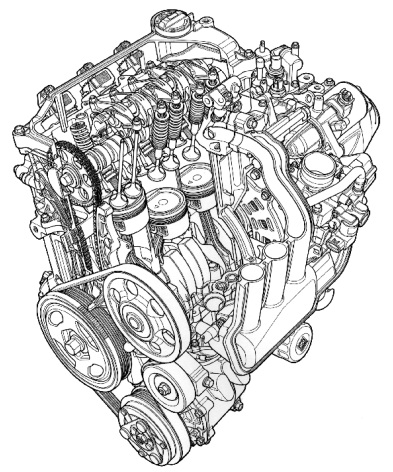

Figure 9. Cutaway view of engine

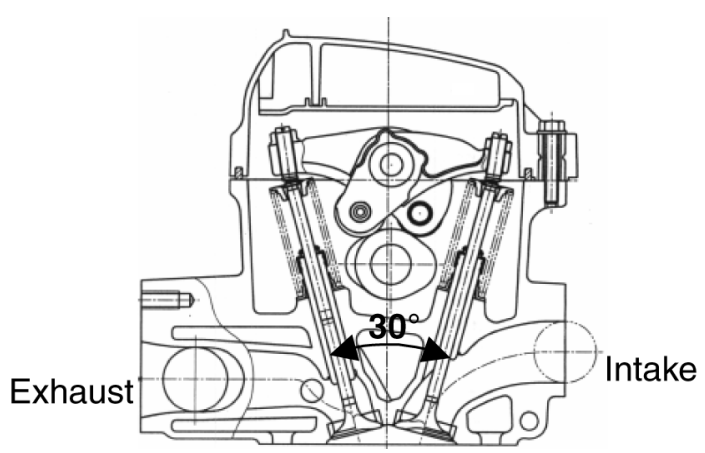

Figure 10. Section view of cylinder

7.4. REDUCTION OF MECHANICAL LOSS - In addition to improvement of the indicated heat efficiency, reduction of mechanical loss is also important to improve fuel 
economy. To achieve this, the following the low friction technologies were used.

- Roller coaxial VTEC mechanism

- Piston micro-dimple treatment

- Offset cylinder structure

- Low tension piston rings

- Carburized connecting rods

The roller coaxial VTEC structure (Fig. 11) is an adaptation of technology used in the Honda S2000 (high output sportscar engine) to a single-cam VTEC mechanism. The camshaft drive loss was reduced by $70 \%$ using a needle roller bearing in the area where the rocker arm slides on the camshaft. In addition, simultaneous reduction in both weight and size were achieved by incorporating the VTEC switching piston into the roller bearing inner shaft.

Piston micro-dimple treatment consists of treating the surface of the piston skirt to create a micro-dimple surface. This increases the oil film retention performance and can reduce friction by approximately $30 \%$ when lowfriction oil is used.

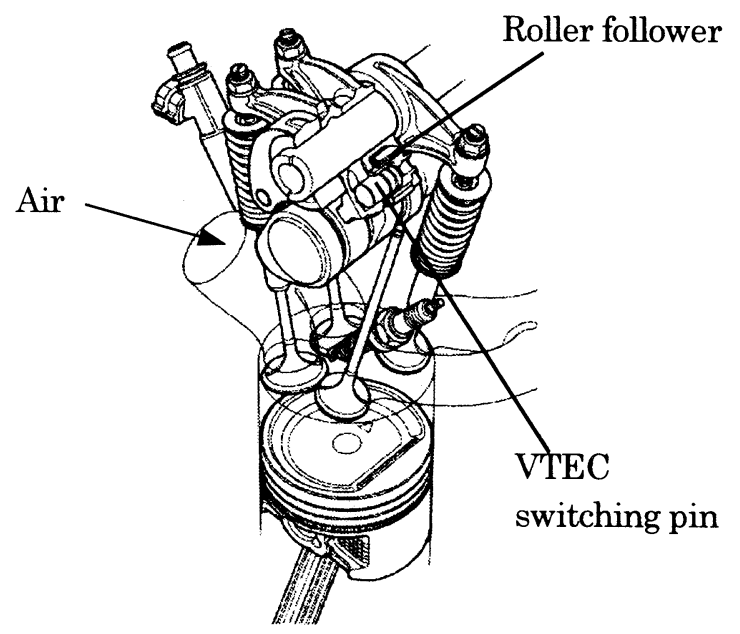

Figure 11. Section view of Roller VTEC

These effects resulted in the development of a $0 \mathrm{~W}-20$ grade low viscosity oil that complies with ILSAC standards. The friction reducing effects of super-low viscosity oil were measured by engine motoring. These measurement results are shown in Fig. 12. In the current technology engine, the HTHS viscosity at the limit friction value was approximately $2.5 \mathrm{mPas}$. Being used together with the advanced low friction engine, the limit value was lower than the current technology engine

These low friction technologies have vastly reduced the overall engine friction, as shown in Fig. 13. In total, they have realized a reduction in friction of $10 \%$ or more compared to a conventional 1.0 liter engine design .
Table.3 OIL specification

\begin{tabular}{|l|c|c|c|c|c|}
\hline \multicolumn{2}{|c|}{} & \multicolumn{2}{c|}{ Developed oil } & Current oil \\
\hline \multicolumn{2}{|l|}{ SAE viscosity grade } & OW-20 & Low vis. & $5 \mathrm{~W}-30$ \\
\hline $\begin{array}{l}\text { Kinematic } \\
\text { viscosity }\end{array}$ & $@ 100^{\circ} \mathrm{C}$ & $\mathrm{mm}^{2} / \mathrm{s}$ & 8.2 & 7.1 & 10.2 \\
\hline Viscosity index & 186 & 185 & 189 \\
\hline $\begin{array}{l}\text { HTHS } \\
\text { viscosity }\end{array}$ & $@ 150^{\circ} \mathrm{C}$ & $\mathrm{mPas}$ & 2.6 & 2.4 & 2.9 \\
\hline $\begin{array}{l}\text { CCS } \\
\text { viscosity }\end{array}$ & $@-25^{\circ} \mathrm{C}$ & $\mathrm{mPas}$ & - & - & 2680 \\
\cline { 2 - 7 } & $-30^{\circ} \mathrm{C}$ & $\mathrm{mPas}$ & 3050 & 2160 & - \\
\hline \multicolumn{2}{|l|}{ Evaporation loss } & $\%$ & 16 & 22 & 17 \\
\hline
\end{tabular}
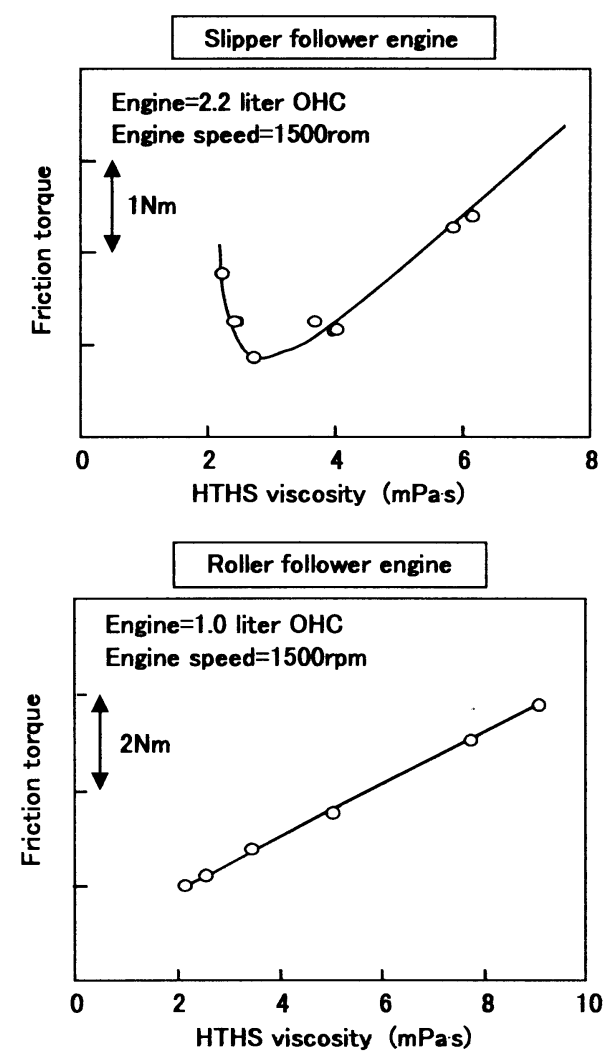

Figure 12. Limit in friction reduction

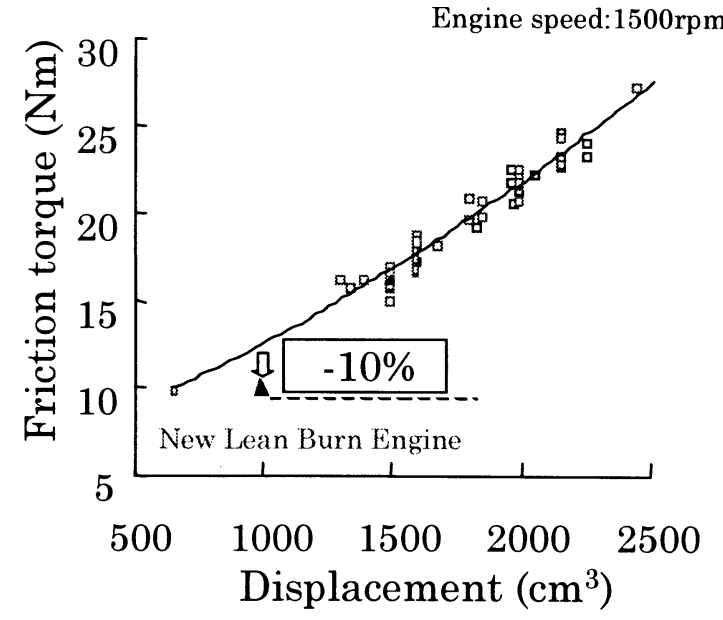

Figure 13. Engine friction 
7.5. WEIGHT REDUCTION - The structure and materials of almost all parts in this engine have been reviewed with the aim of creating the lightest engine in the world in the 1.0 liter class. This weight reduction extends even to the "skeleton structure technology" and "materials technology" fields carburized connecting rods as used on the S2000 (high output sportscar engine). Carburization strength enhancement technology contributes greatly to increasing engine operational speed. We applied this strength enhancement technology to create a slim connecting rod design for the IMA engine. This resulted in a weight reduction of approximately $30 \%$ compared to conventional connecting rods.

Most oil pans are made of steel plate or aluminum alloy. Conventional magnesium materials have had problems withstanding the high temperatures of engine oil. In contrast to conventional materials, which experience a significant drop in creep strength at $120^{\circ} \mathrm{C}$ or higher, we have developed a new magnesium oil pan (Fig. 14) which ensures sufficient creep strength up to $150^{\circ} \mathrm{C}$.

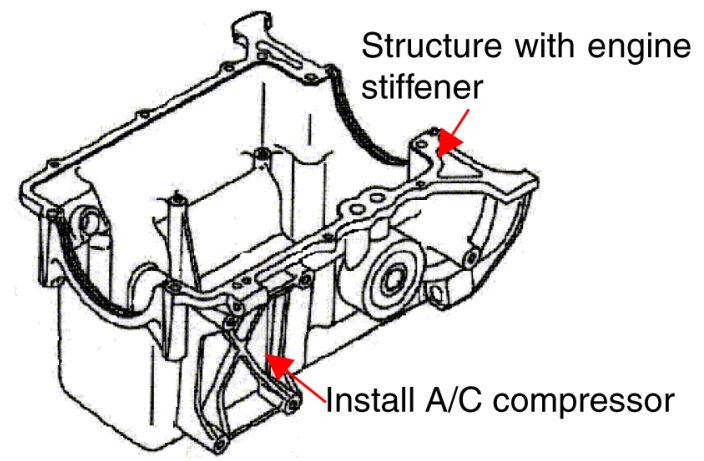

Figure 14. Magnesium Oil Pan

This oil pan is fastened using steel bolts with aluminum washers to prevent galvanic corrosion. The oil pan weight is $35 \%$ lighter than an aluminum oil pan, for a reduction in weight that is comparable to the ratio between the specific masses of the two metals.

In order to expand the application of plastic parts, plastic materials were adopted for the intake manifold, cylinder head cover, water pump pulley, and intake system parts. These changes brought the discrete dry weight of the engine to less than $60 \mathrm{~kg}$, which is the lightest weight in the world for the 1.0 liter class.

\subsection{EXHAUST EMISSION PERFORMANCE -} Technology for simultaneously achieving both lean burn and low exhaust emissions was adopted in this engine, achieving a notable reduction in NOx emissions.

Combustion was improved by putting the exhaust system to the rear of the engine (Fig. 15). In addition, the exhaust manifold was integrated with the cylinder head and a NOx adsorption catalyst which reduces NOx emissions during lean burn operation was also newly developed.

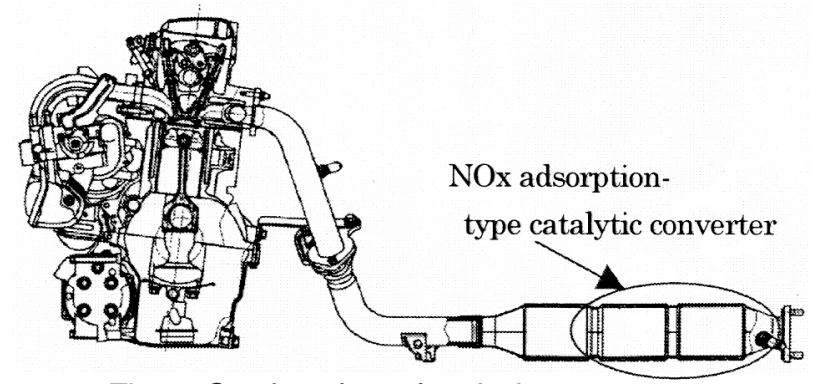

Figure 15. Section view of emission system

7.6.1. Integrated Exhaust Manifold and Cylinder Head Conventional cylinder heads have independent exhaust ports for each cylinder and a separate exhaust manifold acts to converge these exhaust ports into a single port is then mounted to the head. However, the new head on the Insight has a structure which converges the exhaust ports into a single port inside the head, as shown in Fig. 16. This greatly reduces the weight. In addition, the small heat radiating surface area reduces the exhaust gas heat loss, thus enabling early catalyst activation.

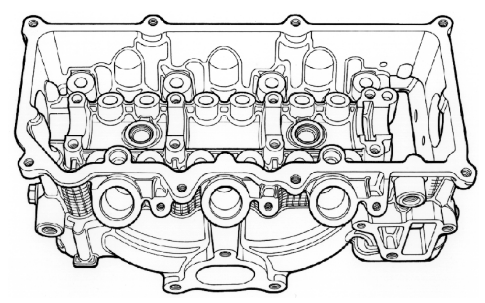

Figure 16. View of Head

7.6.2. Lean NOx Catalyst - The catalyst system on the Insight combines a conventional three-way catalyst with NOx adsorbing materials. The NOx conversion mechanism of the newly developed catalyst is shown in Fig. 17. The NOx in the exhaust gas is adsorbed and separated by the NOx adsorption action of the catalyst during lean engine operating conditions. Conventional three-way catalyst operation reduces part of the NOx to nitrogen and oxidizes most of the $\mathrm{HC}$ and $\mathrm{CO}$ to $\mathrm{CO}_{2}$ and $\mathrm{H}_{2} \mathrm{O}$ during lean operation. However, since the exhaust gas contains large amounts of oxygen, there is relatively little NOx reduction with the three-way catalyst and most of the NOx is stored on the surface of the adsorbing material. When the exhaust is held at the theoretical air fuel ratio (stoichiometry) or richer air-fuel ratio, the adsorbed NOx is reduced to nitrogen using $\mathrm{HC}$ and $\mathrm{CO}$ as reducing agents. The adsorbent is regenerated at the same time. Thus, NOx, $\mathrm{HC}$ and $\mathrm{CO}$ are effectively converted using the three-way catalytic action of the catalyst combined with the NOx adsorber.

This type of catalyst exhibits superior conversion performance during both lean operation and stoichiometric operation by switching between lean and stoichiometry operating conditions. It is essential to 
create a regenerative atmosphere before the NOx adsorption capacity becomes overloaded. This catalyst directly adsorbs NOx during lean burn engine operation and the adsorbed NOx is then reduced and exhausted as harmless nitrogen (N2) during stoichiometric operation.
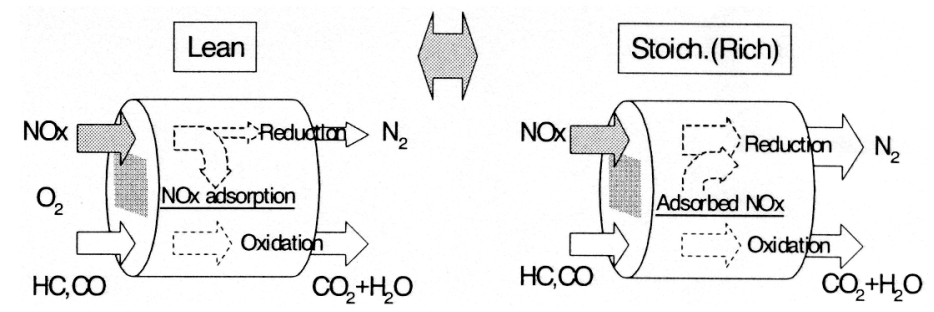

Figure 17. Exhaust gas purification mechanism

This catalyst is characterized by the direct adsorption of NOx to the catalyst surface during lean operation. Adsorption on the catalyst surface, instead of absorption as a compound inside the surface, facilitates conversion during reduction and also provides superior durability at high temperatures. This adsorptive type catalyst reduces NOx emissions during lean burn operation to $1 / 10$ the level of the conventional three-way catalyst. It should be noted that the adsorption and conversion performance of this type of catalyst is sensitive to sulfur levels in the fuel, as sulfur can compete for the active NOx adsorbing sites. As a conventional three-way catalyst has virtually no NOx reduction during lean-operation, the lean burn operating range typically has to be reduced to keep NOx emissions down. Use of an adsorptive type catalyst maintains the full lean burn range and improves fuel economy, even while reducing NOx.

This vehicle can also satisfy the EU2000 standards, making this a highly efficient lean burn engine that complies with exhaust emissions standards throughout the world.

\section{CONCLUSION}

This paper presents a general overview of the recently developed motor assist hybrid powertrain, as well as a description of its various components and its output and emission performance. This hybrid power train simultaneously achieves ultra low fuel consumption and low exhaust emissions. It also achieves a compact, lightweight power train layout. We believe this system advances $21^{\text {st }}$ century automotive technology toward regional and global environmental goals.

\section{REFERENCES}

1. Aoki, Kaoru, et al.: "Development an Integrated Motor Assist Hybrid System", JSAE No. 98-99 161

2. Yamaguchi, Tetsuro: "CVT Control in the HONDA Hybrid 'IMA'", No. 9908 JSAE SYMPOSIUM, Latest Motive Power Transmission Technologies '99, p.3740
3. Ohno, Hiroshi, et al.: "Development of a NOx Adsorptive Reaction Type Three-Way Catalyst", HONDA R\&D Technical Review, Vol. 11 No. 2 (October 1999), p.45-50

4. Fukuo, Koichi, et al.: "Development of the Ultra Low Fuel Consumption Hybrid Car 'Insight'", HONDA R\&D Technical Review, Vol. 11 No. 2 (October 1999), p.1-8

5. Hideki Tanaka, et al : "The Effect of OW-20 Low Viscosity Engine Oil on Fuel Economy", SAE Paper No.1999-01-3468,Fuels and Lubricants meeting and Exposition, Toronto, Ontario, Canada, October 1999.

6. Aoki, Kaoru, et al.: "An Integrated Motor Assist Hybrid System", SAE Paper No.2000-01-2059, Government / Industry Meeting, Washington, D.C., USA 